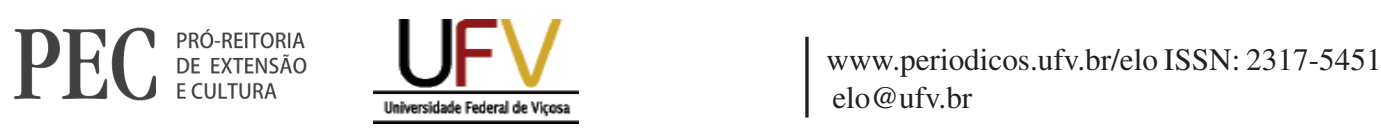

\title{
Extensão Rural Agroecológica: experiências para (trans) formação no Ensino Superior em Agroecologia
}

\author{
Ana Paula de Oliveira Amaral Mello ${ }^{1}$, Renata Evangelista de Oliveira ${ }^{2}$
}

\begin{abstract}
Resumo: A Agroecologia vem se constituindo como uma das bases de um novo paradigma de Desenvolvimento Rural $e$, nessa abordagem, a Extensão Rural é um instrumento fundamental no processo de construção de saberes: agentes da extensão rural são agentes de transformação. Este trabalho evidencia ações em Extensão Universitária, pautadas no conceito de Extensão Rural Agroecológica, que vêm acontecendo, por iniciativa de educandos, no Centro de Ciências Agrárias da Universidade Federal de São Carlos (Campus Araras), desde 2009.
\end{abstract}

Palavras-chave: Desenvolvimento rural. Extensão rural agroecológica. Saber dialógico.

Área Temática: Agroecologia.

\section{Agroecological Extension: experiences for (trans) formation in Higher Education in Agroecology}

Abstract: Agroecology has become one of the bases of a new paradigm of Rural Development and, in this approach, Rural Extension is an instrument in the process of knowledge construction: agents of rural extension are agents of transformation. Here we present actions in University Extension, based on the concept of Agroecological Rural Extension, that happened by initiative of our students, in the Center of Agrarian Sciences, Federal University of São Carlos (Campus Araras), since 2009.

Keywords: Rural development. Agroecological rural extension. Dialogical knowledge.

\section{Extensión Agroecológica: experiencias para (trans) formación en la Enseñanza Superior en Agroecología}

Resumen: La Agroecología se viene constituyendo como una de las bases de un nuevo paradigma de Desarrollo Rural y, en ese abordaje, la Extensión Rural es un instrumento fundamental en el proceso de construcción de saberes: agentes de la extensión rural son agentes de transformación. Este trabajo evidencia algunas acciones en Extensión Universitaria, pautadas en el concepto de Extensión Rural Agroecológica, que vienen sucediendo, por iniciativa de educandos, en el Centro de Ciencias Agrarias, Universidad Federal de São Carlos (Campus Araras), desde 2009.

Palabras clave: Desarrollo rural, Extensión rural agroecológica, Conocimiento dialógico.

\footnotetext{
${ }^{1}$ Professora Doutora do curso de Graduação em Agroecologia da Universidade Federal de São Carlos - UFSCar, Araras - SP, Brasil. Rodovia Anhanguera, km 174, CP 153, Cep 13.600-970,Email: apamello@ufscar.br.

${ }^{2}$ Professora Doutora dos cursos de Graduação em Agroecologiae de Pós Graduação em Agroecologia e Desenvolvimento Rural da Universidade Federal de São Carlos - UFSCar, Araras - SP, Brasil.
} 


\section{INTRODUÇÃO}

\section{Aportes teóricos sobre Agroecologia e Extensão Rural}

AAgroecologia é definida como uma ciência ou área do conhecimento, como um movimento social e/ou político e ainda como a aplicação de todo um conjunto de práticas agrícolas com enfoque ecológico (WEZEL et al., 2009; LO SARDO; FIGUEIREDO, 2015), que apresenta ferramentas para se estudar, compreender, desenhar e manejar agroecossistemas complexos, produtivos e voltados à conservação e ampliação da biodiversidade (ALTIERI, 2004). Em Agroecologia, procura-se construir uma nova abordagem para a Agricultura e o Desenvolvimento Rural, assumindo que princípios e métodos ecológicos pressupõem suas bases fundamentais e que a agricultura não tem apenas um papel econômico e produtor de alimentos, mas funções ambientais, culturais e sociais (ASSIS, 2006; NICHOLS et al., 2016).

A paisagem rural brasileira é múltipla, heterogênea, sócio e biodiversa; nela inseridos os agroecossistemas são compreendidos como sistemas sociais, e se pressupõe o território rural como um espaço socialmente construído. A promoção de mudanças nas formas de se praticar a agricultura nesse contexto necessita de uma abordagem interdisciplinar e que privilegie a valorização de saberes locais (ABREU et al., 2016).A Extensão também deve ser vista sob uma nova perspectiva, com uma nova abordagem, como um instrumento fundamental no processo de construção de saberes (CAPORAL; DAMBRÓS, 2017). Para Freire (1983) a Extensão deve ser educativa, e não deve substituir um conhecimento (tradicional, popular, local) por outro (pacote ensinado nas universidades), mas somar conhecimentos e abrir espaço para o diálogo. Algumas políticas públicas vêm buscando esse viés para a Extensão no país, o Plano Nacional de Extensão (PNE 2011-2020), por exemplo, definiu diretrizes para a Extensão Universitária que devem estar presentes em todas as ações de Extensão em quatro eixos: (i) impacto e transformação, (ii) interação dialógica, (iii) interdisciplinaridade, (iv) indissociabilidade entre ensino, pesquisa e extensão.

Nesse contexto, a Extensão Rural é fortalecida pela Agroecologia, que traz em suas bases a valorização dos saberes populares e tradicionais, a busca pela emancipação e a construção de autonomia para transformação da realidade (OLIVEIRA; VASCONCELOS, 2016). Uma nova Extensão Rural vem aos poucos se tornando realidade no Brasil, a chamada Extensão Rural Agroecológica, respeitando as condições específicas de cada agroecossistema e apoiando a preservação e o resgate da diversidade biológica e cultural (CAPORAL; DAMBRÓS, 2017).

\section{Breves apontamentos sobre o ensino formal em Agroecologia e o ensino superior em Agroecologia da Universidade Federal de São Carlos (UFSCar)}

Os princípios e diretrizes para a Educação em Agroecologia, sistematizados por Aguiar et al. (2013) apontam a importância da indissociabilidade entre ensino, pesquisa e extensão, e de superação da dicotomia 
entre teoria e prática. Sugerem a formação numa perspectiva de "redes de aprendizagem", referenciada na realidade e tomando a vivência das comunidades como conteúdo problematizador para o processo de ensino aprendizagem. Para esses autores, a educação formal em Agroecologia não se dá de uma única forma, e abrange diferentes espaços e processos, em diferentes níveis educacionais. Há que se considerar disciplinas em espaços formais aliadas a práticas e vivências educativas de campo, orientadas por pesquisa e extensão, e múltiplas relações entre as instituições de ensino e as comunidades. Também atividades extracurriculares que enriquecem esses processos, protagonizadas por iniciativas coletivas, devem ser incluídas nessa formação (AGUIAR et al., 2013).

No Bacharelado em Agroecologia do Centro de Ciências Agrárias (CCA/UFSCar) em Araras, o desafio é o desenvolvimento de uma visão sistêmica, desde o semestre ingressante, pensando-se as disciplinas de forma inter-relacionada e identificando interações e conexões indissociadas entre teoria e prática. O Projeto Pedagógico do Curso (PPC) prevê a inclusão dessa abordagem sistêmica como uma de suas bases fundamentais. Nossos alunos são iniciados nas bases teóricas fundamentais da Agroecologia, e sobre estrutura e funcionamento de agroecossistemas em disciplinas formais. À medida que avançam na matriz curricular, vivenciam práticas agroecológicas e de manejo de agroecossistemas, em aulas práticas, estágios de vivência, estágios de férias, mutirões e atividades de extensão, em espaços formais e não formais.

Para Altieri et al. (2015) uma tarefa fundamental da Agroecologia é compreender os mecanismos subjacentes à sustentabilidade e à resiliência dos sistemas agrícolas tradicionais, e depois traduzi-los em tecnologias apropriadas a nível local, aplicáveis aos mais diferentes agroecossistemas. Para tanto, a matriz de disciplinas obrigatórias do curso é dividida em eixos temáticos e visa gerar embasamento teórico e possibilitar um olhar sistêmico e abrangente sobre a realidade, para a construção de uma nova perspectiva de Extensão Rural, que permita a análise e o diálogo, resultando em interferências positivas embasadas nos fundamentos da Agroecologia e do manejo agroecológico.

\section{OBJETIVO}

Construir um panorama geral sobre as ações relacionadas à Extensão Rural Agroecológica na UFSCar, concebidas e desenvolvidas pelos educandos em Agroecologia.

\section{METODOLOGIA}

Avaliar todo processo da Extensão Rural na UFSCar, fazendo um levantamento das ações desde 2009 e as elencando a partir de uma perspectiva temporal, com a construção de uma linha do tempo. 


\title{
RESULTADOS E DISCUSSÃO
}

\section{Relato: apresentação de experiências com a extensão rural agroecológicana UFSCar Campus Araras}

\begin{abstract}
É necessário diálogo e comunicação do extensionista rural com o produtor, para que ambos busquem soluções (...) sem que o técnico imponha o seu saber como incontestável. É no diálogo que se torna possível uma relação de transformação da realidade, na medida em que o receptor não é mais visto como objeto e 'depósito' de conhecimento, mas, se torna sujeito de transformação prática. (WIVALDO et al., 2018, p. 27).
\end{abstract}

O início dessa nova abordagem em extensão rural, no Centro de Ciências Agrárias, no Campus Araras, partiu de um grupo de alunos da primeira turma de Bacharelado em Agroecologia e de alunos do Mestrado em Agroecologia e Desenvolvimento Rural que, motivados por um senso comum - o de colocar em prática os conhecimentos adquiridos em sala de aula- formaram um coletivo (Coletivo em Agroecologia e Permacultura Pés Vermelhos) no ano de 2009. Desde então, muitas ações foram e estão sendo construídas e desenvolvidas sob responsabilidade de professores e alunos do curso. Todas as atividades de extensão que aqui seguem listadas relacionam-se a atividades concebidas, planejadas e desenvolvidas por iniciativa dos educandos em Agroecologia, apoiadas por assentados rurais, estudantes de pós-graduação, docentes e servidores técnicos da Universidade Federal de São Carlos.

Foram quase sessenta atividades realizadas de 2009 a 2018, que podem ser divididas em dois grandes conjuntos de ações: (i) Atividades de extensão por alunos, agricultores e colaboradores em assentamentos (Araras I, II, III e IV) e propriedades rurais da cidade de Araras: destinados a formações, mutirões e ações coletivas específicas, focadas no diagnóstico e resolução de problemas locais e melhoria da estrutura de lotes, propriedades rurais e assentamentos, com base em princípios agroecológicos; (ii) Atividades de extensão voltadas à formação em práticas agroecológicas nas dependências do Centro de Ciências Agrárias (Figura 1).

Nas avaliações das atividades, os participantes discorreram sobre como esses eventos foram importantes não só para a formação, mas para o fortalecimento de uma rede diversificada de pessoas de diferentes municípios da região, difundindo, de forma democrática e popular, as práticas agroecológicas para toda a comunidade do entorno da Universidade, sendo de suma importância para a construção de um modelo contra hegemônico de produção de alimentos.

Ainda, todas essas atividades de imersão permitiram aos participantes compartilhar conhecimentos, aplicar conceitos teóricos e dialogar com os diferentes atores envolvidos nos processos de produção, tendo em vista que em sistemas socioecológicos, não é apenas a produção final de bens que é levada em consideração, mas todo conhecimento tradicional, cultural e social e as possíveis pesquisas que são realizadas a partir daquela experiência. 


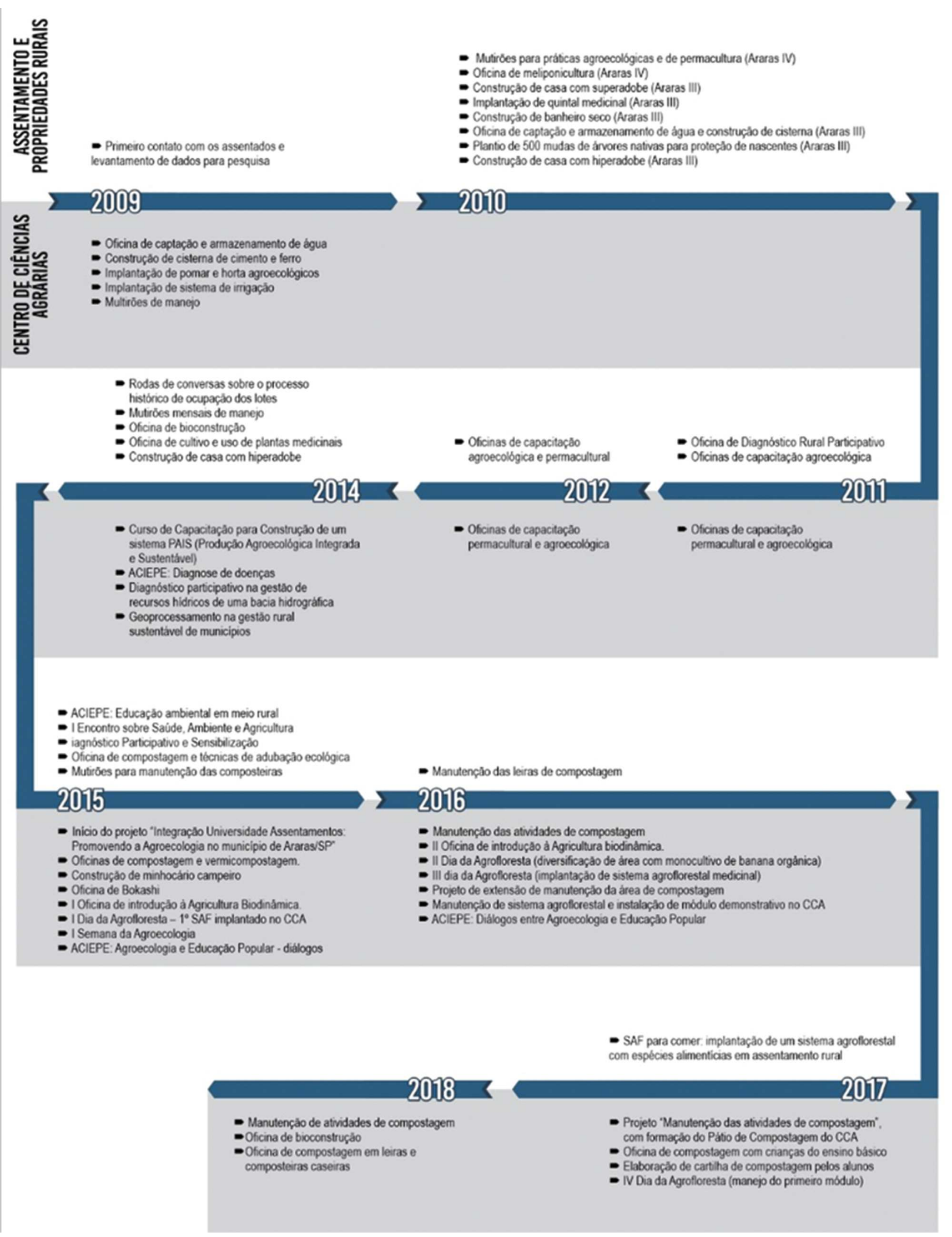

Figura 01 - Linha do tempo com a realização de atividades de extensão, em assentamentos e propriedades rurais no município de Araras (SP) e no Centro de Ciências Agrárias, realizadas por iniciativa dos educandos do Bacharelado em Agroecologia, de 2009 a 2018. 


\section{CONCLUSÕES}

A Extensão Rural Agroecológica é baseada num processo de intervenção de caráter educativo e transformador, e com metodologias que permitem o desenvolvimento de uma prática social em que seus atores buscam a construção e sistematização de conhecimentos que os levem a agir conscientemente sobre a realidade (BROSLER et al., 2010). Compreende-se que essa nova extensão promove a interação e a troca de saberes entre a comunidade universitária e a sociedade, sendo um instrumento indispensável à plena realização da Universidade como instrumento emancipatório. Ela funciona como processo educativo emancipador, construtivista e democrático, que se realiza mediante técnicas e metodologias participativas, capazes de contribuir para o fortalecimento da cidadania e a construção do Desenvolvimento Rural Sustentável (WIVALDO et al., 2018).

As atividades aqui elencadas apresentam essas características, todas são fruto de demandas de agricultores e agricultoras de assentamentos e propriedades rurais familiares, e do empenho e organização coletiva dos discentes dos cursos de graduação e pós-graduação em Agroecologia do CCA, à luz de conhecimento teórico e construtivista. A Extensão Aural agroecológica no Campus Araras passou por um longo processo de semeadura, germinou e está na fase de desenvolvimento, dando bons frutos. Diversos projetos foram e estão sendo elaborados e executados, gerando projetos de iniciação científica e tecnológica (com financiamento dos Programas Institucionais de Iniciação Científica e Tecnológica CNPq/UFSCar), atividades com bolsas de extensão (financiadas pela Pró-Reitoria de Extensão da UFSCar), projetos sociais e trabalhos de conclusão de curso orientados por professores do Departamento de Desenvolvimento Rural (DDR) e de outros departamentos e campi da UFSCar. Entendemos que essas atividades de extensão, de caráter interdisciplinar, concebidas a partir de demandas e da realidade local de agricultores e agricultoras, assentados e assentadas rurais do município e região, e da comunidade do Campus, são bases fundamentais na formação dos educandos em Agroecologia na UFSCar, e na construção e fortalecimento de uma ampla rede de extensão rural agroecológica e disseminação de conhecimentos na região de Araras, SP.

\section{AGRADECIMENTOS}

As autoras agradecem ao Coletivo Pés Vermelhos, Bruna Silva, Diogo Mantovanelli, Geovane Marques, Lucas Bevilacqua, Thais Menina, Adriana Sais, Rodolfo Figueiredo, e Manoel Baltasar da Costa, idealizadores e realizadores das ações. À Pró Reitoria de Extensão UFSCar, Diretoria e Comitê de Eventos do CCA, Centro Vocacional Tecnológico em Agroecologia e Produção Orgânica, FCA/UNESP, ITESP, Cooperativa de Assentados e Agricultores Rurais e Secretaria de Serviços Públicos de Araras. Aos agricultores e agricultoras, grandes mentores e estimuladores desse processo. 


\section{REFERÊNCIAS}

ABREU, L. S.; BELLON, S.; TORRES, T. Z. A contribuição das ciências e do movimento social para a agroecologia no Brasil. ComCiência - Revista Eletrônica de Jornalismo Científico. Edição de Outubro, 2016. Disponível em: <http://www.comciencia.br/comciencia/?section=8\&edicao=127\&id=15>. Acesso em: 30 mar. 2017.

AGUIAR, M.V.A.; MATTOS, J. L. S.; LIMA, J. R. T. et al. Princípios e diretrizes da educação em Agroecologia. In: I Seminário Nacional de Educação em Agroecologia. Associação Brasileira de Agroecologia, 2013, 16 p.

ALTIERI, M. A. Agroecologia: A dinâmica produtiva da agricultura sustentável. Porto Alegre RS: Editora UFRGS, 2004.

ALTIERI, M. A.; NICHOLS, C.; HENAO, A.; LANA, M. A. Agroecology and the design of climate change-resilient farming systems. Agronomy and Sustainable Development, v. 35, p. 869-890, 2015.

ASSIS, R. L. Desenvolvimento rural sustentável no Brasil: perspectivas a partir da integração de ações públicas e privadas com base na Agroecologia. Economia Aplicada, v.10, n.1, p.75-89, 2006.

BROSLER, T. M., OLIVEIRA, E.R. L., BERGAMASCO, S.P.P. Métodos na Nova Extensão Rural: caminho para a participação de quem? In: CONGRESSO BRASILEIRO DE ECONOMIA ADMINISTRAÇÃO E SOCIOLOGIA RURAL, 48, 2010, Campo Grande. UFMS, 2010. Disponível em: <http://www.sober.org.br/palestra/15/396.pdf>. Acesso em: 20 nov. 2016.

CAPORAL, F. R.; DAMBRÓS, O. Extensão Rural Agroecológica: experiências e limites.Redes, v. 22, n. 2, p.275-297, 2017.

FREIRE, P. Extensão ou comunicação? 20 ed. Rio de Janeiro RJ: Paz e Terra. 1983.

LO SARDO, P. M.; FIGUEIREDO, R. A. A construção do campo da Agroecologia e sua relação com o desenvolvimento rural. Interthesis, v.12, n.1, p. 337-360, 2015.

NICHOLS, C.; ALTIERI, M. A.; VAZQUEZ, L. Agroecology: principles for the conversion and redesign of farming systems. Journal of Ecosystem \& Ecography, v.5, p. 1-8, 2016.

OLIVEIRA, R. E.; VASCONCELOS, V.O. Diálogos entre Agroecologia e Educação Popular: práxis e extensão. Revista ELO, v. 5, n. 1, p. 34-39, 2016.

WEZEL, A.; BELLON, S.; DORÉ, T.; FRANCIS, C.; VALLOD, D.; DAVID, C. Agroecology as a science, a movement or a practice. A review. Agronomy for Sustainable Development, v. 29, p. 503-515, 2009.

WIVALDO, J. N. S.; COUTO, S. F. M.; PEREIRA, V. S.; REZENDE, D. R.; CARVALHO, F. C. E PEREIRA, M.D. A percepção da extensão rural no âmbito da graduação nas ciências sociais e agrárias na UFLA. Revista ELO, v. 7, n. 1, p. 15-27, 2018.

Submetido em: 14/03/2019 Aceito em: 24/03/2020. 